DOI: 10.15587/2706-5448.2021.243069

Article type «Reports on Research Projects»

\section{Yan Liu, Sergei Sabadash, Zhenhua Duan}

\title{
RESEARCH OF PHYSICOCHEMICAL PROPERTIES AND ANTIOXIDANT ACTIVITY OF BEETROOTS AS AFFECTED BY VACUUM MICROWAVE DRYING CONDITIONS
}

The object of research is the beetroots, dried by vacuum microwave drying at different conditions. Physicochemical properties and antioxidant activity of beetroots were studied using vacuum microwave drying at different microwave power (500, 1000, and $1500 \mathrm{~W})$, vacuum degree (-0.05, -0.07, and-0.09 MPa) and sample thickness (2, 4, and $6 \mathrm{~mm})$. A colorimeter was used to evaluate the color quality of beetroots. Colorimetric methods were used to determinate contents of betalain, ascorbic acid and total flavonoid, and antioxidant activity (ferric reducing antioxidant power assay) of beetroots.

Results showed that the drying time decreased with increasing microwave power and vacuum degree, while increased significantly with the increase of sample thickness. The lightness $\left(L^{*}\right)$ of dried beetroots was higher than that of fresh beetroots. The values of redness $\left(a^{*}\right)$ increased with the increase of vacuum degree. The values of yellowness $\left(b^{*}\right)$ increased with the growth of vacuum degree and microwave power, while reduced as the sample thickness added. The total color difference $(\Delta E)$ of dried beetroots reduced with increasing vacuum degree, and displayed the lowest value (5.95) at a vacuum degree of -0.09 MPa as compared to fresh beetroots. The content of betacyanin, betaxanthin and ascorbic acid displayed a declining tendency with the growth of microwave power, while increased with the increase of vacuum degree. And the total flavonoid content of beetroots illustrated a decreasing tendency with the increase of vacuum degree, microwave power and sample thickness. The ferric reducing antioxidant power (FRAP) of dried beetroots decreased significantly with the increase of microwave power, and showed the highest value (14.70 mg trolox equivalents/g) at a microwave power of $500 \mathrm{~W}$.

The most favorable conditions for vacuum microwave drying of beetroots were microwave power of $500 \mathrm{~W}$, vacuum degree of -0.09 MPa and sample thickness of $2 \mathrm{~mm}$. It leads to better physicochemical properties and higher antioxidant activity of dried beetroots. The dried beetroots can be used as functional foods and valueadded food products.

Keywords: dried beetroots, vacuum microwave drying, betalain, total flavonoid, colorimetric methods, antioxidant activity.

How to cite

Liu, Y., Sabadash, S., Duan, Z. (2021). Research of physicochemical properties and antioxidant activity of beetroots as affected by vacuum microwave drying conditions. Technology Audit and Production Reserves, 5 (3 (61)), 40-45. doi: http://doi.org/10.15587/2706-5448.2021.243069

\section{Introduction}

Beetroot (Beta vulgaris L.) is one of important root vegetables and rich in carbohydrates, protein, fat, betalains, ascorbic acid, carotenoids, polyphenols, flavonoids, saponins, nitrate, vitamins, minerals, and essential and non-essential amino acids [1]. Beetroot as a food source for humans is consumed fresh (salad, juice) as well as cooked, pickled, or canned all over the world [2]. Beetroot soup is a popular meal in Eastern Europe, and pickled beetroot is a traditional food of the South America. Nowadays a large proportion of beetroot is used for commercially pickles production [1]. Beetroot can also be used as natural colorant, to coloring a variety of foods like candies, cheese, yogurts, ice cream, noodles, sausages, and pasta [3]. Beetroot contains a lot of bioactive compounds, which have many health benefits including antioxidant, antianemic, anti-hypertensive, antipyretic, antibacterial, anti-inflammatory, anti-diabetic, detoxicant, anticarcinogenic and hepato-protective activities, detoxicant, diuretic and wound healing benefits [4-6]

Vacuum microwave drying is one of novel technologies, an efficiently and gentle drying method. The intensive heating of microwave and low boiling point, generated by the vacuum, make the material to be dried at relatively low temperature over a short time, helping to maintain a high 
level of healthy nutrition and sensory quality [7]. There are so many researches on vacuum microwave drying of vegetables and fruits, confirming to preserve color, total phenolic, total flavonoid, and ascorbic acid [8-10]. Fresh beetroots are exposed to spoilage due to its high moisture content. The drying of fresh beetroots can reduce moisture content and water activity, reducing microbial growth, chemical reactions, and enzymatic activity, as well as storage and transport costs [11].

The drying method and drying condition influence the physicochemical properties and antioxidant activity of the final product. Although vacuum microwave drying have been evaluated for drying application of foods, there are no researcher noticed in literature concerning to drying conditions on the physicochemical properties and antioxidant activity of beetroots. Therefore, the aim of this study was to investigate the influence of vacuum microwave drying conditions on the quality of beetroots in terms of drying time, color, total flavonoid content, betalain content, ascorbic acid content, and antioxidant capacity. Thus, the object of research is the beetroots, dried by vacuum microwave drying at different conditions.

\section{Methods of research}

Fresh beetroots were obtained from a local market in Xuzhou city, Jiangsu province, China. Ascorbic acid assay kit (Nanjing Jiancheng Institute of Bioengineering, Nanjing, China); Trolox, rutin, and tri-2-pyridyl-s-triazine (Shanghai yuanye Bio-Technology Co., Ltd, Shanghai, China); Ethanol (Tianjin Zhiyuan Chemical Reagent Co., Ltd, Tianjin, China).

The one-factor-at-a-time method was applied in this study to design experiments with three replications. Investigated factors include microwave power, vacuum degree and thickness. At the beginning of each experiment, fresh beetroots were washed and peeled, and then cut into slices with a diameter of $60 \mathrm{~mm}$. Fresh beetroot slices $(800.0 \pm 5.0 \mathrm{~g})$ were carefully placed on a tray $(610 \times 430 \times 50 \mathrm{~mm})$. The tray was put into a vacuum microwave dryer (WBZ-10, Guiyang Xinqi Microwave Industry Co., Ltd, Guiyang, China) for continuous dehydration at different microwave powers $(500,1000$, and $1500 \mathrm{~W})$, vacuum degrees $(-0.05$, -0.07 , and $-0.09 \mathrm{MPa}$ ) and sample thicknesses (2, 4, and $6 \mathrm{~mm}$ ). Eight different microwave drying conditions are shown in Table 1. The average initial moisture content of beetroots was $90.1 \%$, and the drying process was stopped when the final moisture content of beetroots was below $7.0 \%$ (wet basis), which was considered the final moisture ensuring safe storage.

Table 1

Vacuum microwave drying conditions for drying fresh beetroots

\begin{tabular}{|c|c|c|c|}
\hline Treatment & $\begin{array}{c}\text { Microwave } \\
\text { power, } W\end{array}$ & $\begin{array}{c}\text { Vacuum } \\
\text { degree, MPa }\end{array}$ & $\begin{array}{c}\text { Sample } \\
\text { thickness, mm }\end{array}$ \\
\hline T1 & 1500 & -0.05 & 2 \\
\hline T2 & 1500 & -0.07 & 2 \\
\hline T3 & 1500 & -0.09 & 2 \\
\hline T4 & 500 & 0.08 & 2 \\
\hline T5 & 1000 & 0.08 & 2 \\
\hline T6 & 1500 & 0.08 & 2 \\
\hline T7 & 1500 & 0.08 & 4 \\
\hline T8 & 1500 & 0.08 & 6 \\
\hline
\end{tabular}

In this study, the color parameters of beetroots were determined using a colorimeter (CR-400, Konica Minolta Sensing, Inc., Tokyo, Japan). The CIE Lab color parameters were used to describe the color characteristics of beetroots. Value of $L^{*}$ represents lightness, varies from 0 (black) to 100 (white); $a^{*}$ refers to the region ranging from green $\left(-a^{*}\right)$ to red $\left(+a^{*}\right)$, and $b^{*}$ ranges from blue $\left(-b^{*}\right)$ to yellow $\left(+b^{*}\right)$. The measurements were done 8 times for each sample. Total color difference $(\Delta E)$ indicates the magnitude of color change after drying and was calculated by Equation (1) [12]

$$
\Delta E=\sqrt{\left(L^{*}-L_{0} *\right)^{2}+\left(a^{*}-a_{0} *\right)^{2}+\left(b^{*}-b_{0}\right)^{2}},
$$

where $\Delta E$ is the difference between the color of fresh beetroots and dried beetroots; $L^{*}, a^{*}$, and $b^{*}$ are the color parameters of dried beetroots; $L_{0}{ }^{*}, a_{0}{ }^{*}$, and $b_{0}{ }^{*}$ are the color parameters of fresh beetroots.

Extraction of bioactive compounds. Dried beetroots were grounded, and then passed through a 60-mesh sieve to obtain sample powder. One gram of sample powder was mixed with $15 \mathrm{~mL}$ of $50 \%$ ethanol (v/v) by a vortex mixer (VORTEX-5, Kylin-Bell Instrument Manufacturing Co., Ltd, Jiangsu, China) for $2 \mathrm{~min}$, and then the mixture was centrifuged at $5000 \mathrm{rpm}$ for $10 \mathrm{~min}$ using a centrifuge (L550, Xiangyi Centrifuge Instrument Co., Ltd, Hunan, China). The supernatant was collected, and the residue was extracted twice with $15 \mathrm{~mL}$ of $50 \%$ ethanol (v/v). Supernatants from the three extractions were mixed and diluted to $50 \mathrm{~mL}$ with $50 \%$ ethanol $(\mathrm{v} / \mathrm{v})$, and then stored at $4{ }^{\circ} \mathrm{C}$ for further analysis.

The betalain content of beetroots was determined using the modified colorimetric method, reported in [13].

The ascorbic acid content was determined by the colorimetric method using a detection kit (Nanjing Jiancheng Institute of Bioengineering, Nanjing, China). The results were expressed as milligram per gram of dry weight.

The total flavonoid content was carried out using the aluminum chloride colorimetric method [14]. A calibration curve was obtained using different concentrations $(0-1.0 \mathrm{mg} / \mathrm{mL})$ of rutin. The results were expressed as milligram of rutin equivalent (RE) per gram of dry weight.

The antioxidant activity of dried beetroots was evaluated by the ferric reducing antioxidant power (FRAP) method. The FRAP assay was conducted by the method as described in [15]. Briefly, a FRAP reagent was prepared by mixing $0.01 \mathrm{M}$ TPTZ solution (prepared in $0.04 \mathrm{M} \mathrm{HCl}$ ), $0.02 \mathrm{M} \mathrm{FeCl}_{3}$ solution and $0.3 \mathrm{M}$ acetate buffer $(\mathrm{pH} 3.6)$ at the volumetric ratio of 1:1:10. The diluted extract $(0.2 \mathrm{~mL})$ was fully reacted with $6 \mathrm{~mL}$ FRAP reagent. After incubating at $37{ }^{\circ} \mathrm{C}$ for $10 \mathrm{~min}$, the absorbance was measured at $593 \mathrm{~nm}$ using a visible spectrophotometer (722, Precision Scientific Instruments Co., Ltd, Shanghai, China). A standard curve was built by using a trolox solution as stand and the results were expressed as milligram of trolox equivalent (TE) per gram of dry weight (mg TE/g).

All experiments were conducted at least in triplicate and the results were expressed as mean \pm standard deviation. The analysis of variance (ANOVA) and Tukey's test were performed using SPSS Statistics Version 20 (IBM Corporation, Chicago, IL, USA) to determine significant differences at $95 \%$ level $(p<0.05)$. Figures were drawn using Origin 9.0 (Origin Lab, MA, USA). 


\section{Research results and discussion}

3.1. The drying time of beetroots affected by vacuum microwave drying conditions. The drying time of beetroots at different vacuum microwave drying conditions are exhibited in Fig. 1. The drying time of vacuum microwave drying for beetroots ranged from 33.0 to $87.3 \mathrm{~min}$. The beetroots, dried at a vacuum degree of $-0.09 \mathrm{MPa}$ (T3), showed the lowest drying time $(33.0 \mathrm{~min})$. Meanwhile, the dried beetroots, obtained at a microwave power of $500 \mathrm{~W}$ (T4), required the longest drying time $(87.3 \mathrm{~min})$. The drying time increased with sample thickness of beetroots, but decreased with the increase of microwave power and vacuum degree at the designed levels. As the vacuum degree increased from -0.05 to $-0.09 \mathrm{MPa}$, the drying time of beetroots decreased from 40.3 to $33.0 \mathrm{~min}$. The time to dry fresh beetroots reduced $43.0 \%$ when microwave power increased double (from 500 to $1000 \mathrm{~W}$ ), and when the microwave power was $1500 \mathrm{~W}$, the drying time of beetroots was only $38.9 \%$ of that at a microwave power of $500 \mathrm{~W}$. The drying time of beetroots increased with increasing sample thickness of beetroots. When the sample thickness increases, the distance of internal moisture migration to the surface increases, and the drying time increases accordingly. The drying time was 34.0 min when the sample thickness of beetroots was $2 \mathrm{~mm}$ (T6), which was only $50.5 \%$ of that of beetroots with a sample thickness of $6 \mathrm{~mm}$ (T8). In other words, as the sample thickness of beetroots increased from 2 to $6 \mathrm{~mm}$, the drying time increased by $97.9 \%$.

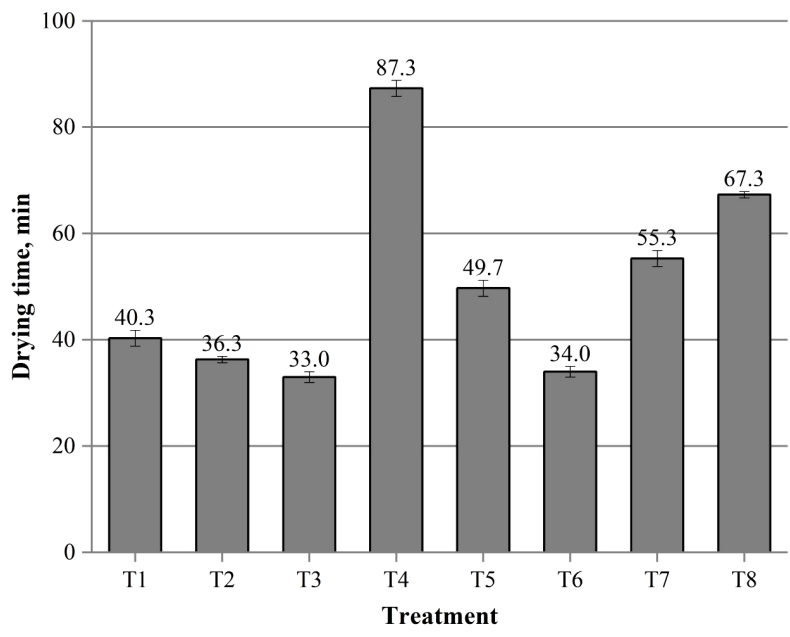

Fig. 1. Drying time of beetroots at different vacuum microwave drying conditions

In this study, higher microwave power and vacuum degree, and smaller sample thickness resulted in less drying time at the designed levels. Similar result has been reported on microwave-vacuum drying of kiwifruit slices [16].

3.2. Color parameters of beetroots. Color is one of important quality factors that affects consumers' acceptability for dried products. The color parameters of beetroots are shown in Table 2 . The $L^{*}$ values of dried beetroots were significantly higher than that of fresh beetroots $(p<0.05)$, demonstrating that dried beetroots are brighter than fresh beetroots. Similar results were also found for obtaining beetroot powder $[17,18]$. The $L^{*}$ values of dried beet- roots differed among eight different drying conditions, with the $L^{*}$ value of T5 samples (the beetroots, dried at a microwave power of $1000 \mathrm{~W}$ ) being the highest (43.51), and that of T2 samples (the beetroots, dried at a vacuum degree of $-0.07 \mathrm{MPa}$ ) being the lowest (39.86). The $a^{*}$ and $b^{*}$ values of all beetroots after vacuum microwave drying were significantly lower than that of fresh beetroots $(p<0.05)$. The value of $a^{*}$ was found to increase with the increase of vacuum degree from -0.05 to $-0.09 \mathrm{MPa}$. The beetroots, dried at $-0.09 \mathrm{MPa}$ (T3), showed the largest $a^{*}$ value (23.97) among eight vacuum microwave drying conditions, while the beetroots with a sample thickness of $4 \mathrm{~mm}$ (T7) showed the lowest $a^{*}$ value (21.05). There was a significant increase in $b^{*}$ with the increase of vacuum degree $(p<0.05)$. The $b^{*}$ value also increased with the increase of microwave power. The beetroots with a sample thickness of $4 \mathrm{~mm}$ (T7) displayed the lowest $b^{*}$ value (2.48), while the beetroots, dried at a vacuum degree of $-0.09 \mathrm{MPa}$ (T3), showed the highest $b^{*}$ value (3.72) among all the vacuum microwave drying conditions. The total color differences $(\Delta E)$ of dried beetroots was between 5.95 and 9.74 in comparison with fresh beetroots. It has been reported, that the $\Delta E$ parameters were between 5.06 and 13.39 for microwave vacuum drying of red beetroot samples [19]. The beetroots, dried at a vacuum degree of $-0.09 \mathrm{MPa}$ (T3), showed the lowest $\Delta E$ (5.95), while the beetroots with a sample thickness of $4 \mathrm{~mm}$ (T7) displayed the biggest $\Delta E$. It has been reported, that the enzymatic reaction and Maillard reaction during the drying process were the main reasons for discoloration of materials [20]. During the vacuum microwave drying process, it can significantly prevent the enzymatic reaction and Maillard reaction, result in a good color characteristics.

Table 2

Color changes of dried beetroots affected by different vacuum microwave drying conditions

\begin{tabular}{|c|c|c|c|c|}
\hline Treatment & $L^{*}$ & $a^{*}$ & $b^{*}$ & $\Delta E$ \\
\hline Fresh & $37.52 \pm 0.66^{\mathrm{e}}$ & $28.47 \pm 0.63^{\mathrm{a}}$ & $6.02 \pm 0.17^{\mathrm{a}}$ & - \\
\hline T1 & $41.26 \pm 0.82^{\mathrm{bc}}$ & $22.77 \pm 0.42^{\mathrm{cd}}$ & $2.70 \pm 0.12^{\mathrm{de}}$ & $7.62 \pm 0.57^{\mathrm{c}}$ \\
\hline T2 & $39.86 \pm 0.89^{\mathrm{d}}$ & $23.23 \pm 0.53^{\mathrm{bc}}$ & $3.00 \pm 0.07^{\mathrm{c}}$ & $6.53 \pm 0.63^{\mathrm{de}}$ \\
\hline T3 & $40.57 \pm 0.76^{\text {cd }}$ & $23.97 \pm 0.41^{\mathrm{b}}$ & $3.72 \pm 0.10^{\mathrm{b}}$ & $5.95 \pm 0.42^{\mathrm{e}}$ \\
\hline T4 & $40.86 \pm 0.90^{\mathrm{bcd}}$ & $22.87 \pm 0.33^{\mathrm{c}}$ & $2.82 \pm 0.09^{\mathrm{cd}}$ & $7.31 \pm 0.29^{\mathrm{cd}}$ \\
\hline T5 & $43.51 \pm 0.59^{\mathrm{a}}$ & $23.80 \pm 0.38^{\mathrm{b}}$ & $3.51 \pm 0.19^{\mathrm{b}}$ & $8.01 \pm 0.51^{\mathrm{bc}}$ \\
\hline T6 & $40.59 \pm 0.63^{\mathrm{cd}}$ & $23.37 \pm 0.48^{\mathrm{bc}}$ & $3.56 \pm 0.17^{\mathrm{b}}$ & $6.46 \pm 0.58^{\mathrm{de}}$ \\
\hline T7 & $42.73 \pm 0.53^{\mathrm{a}}$ & $21.05 \pm 0.21^{\mathrm{d}}$ & $2.48 \pm 0.12^{\mathrm{e}}$ & $9.74 \pm 0.37^{\mathrm{a}}$ \\
\hline T8 & $42.15 \pm 0.67^{\mathrm{ab}}$ & $21.97 \pm 0.26^{\mathrm{c}}$ & $2.67 \pm 0.10^{\mathrm{de}}$ & $8.67 \pm 0.49^{\mathrm{b}}$ \\
\hline
\end{tabular}

Note: in the same column, there are significant differences among those with different superscript letters $(p<0.05)$, and those with the same letters are not significantly different $(p>0.05)$

As a result, beetroots, dried at a vacuum degree of $-0.09 \mathrm{MPa}$ (T3), had the most desirable color among the beetroots, dried at eight different vacuum microwave drying conditions, with the lowest $\Delta E$ and the values of $L^{*}$, $a^{*}$ and $b^{*}$ close to the fresh one, owing to the highest vacuum degree and the shortest drying time.

3.3. Bioactive compounds of dried beetroots. Contents of bioactive compounds in dehydrated beetroots, dried by different vacuum microwave drying conditions, are displayed 
in Table 3. As we know, vacuum treatment can remove available oxygen or at low oxygen levels reduce pigment degradation better than under air atmosphere [19].

As shown in Table 3, betacyanin contents of dried beetroots increased significantly with increasing vacuum degree from -0.05 to $-0.09 \mathrm{MPa}(p<0.05)$. It was also observed, that an increase in vacuum degree resulted in a significant increase in betaxanthin content $(p<0.05)$. It is well known, that betalain is sensitive to oxidation. Available oxygen removal under vacuum or under low oxygen levels results in decreased pigment degradation more than under air atmosphere. With an increase in microwave power from 500 to $1500 \mathrm{~W}$, there was a significant decrease in betacyanin content $(p<0.05)$. There was also a decrease in betaxanthin content with the increase of microwave power. However, when the sample thickness of beetroots were $2 \mathrm{~mm}$ and $6 \mathrm{~mm}$, there was no significant difference in contents of betacyanin and betaxanthin $(p>0.05)$. In conclusion, the highest contents of betacyanin $(4.65 \mathrm{mg} / \mathrm{g})$ and betaxanthin $(3.34 \mathrm{mg} / \mathrm{g})$ were found in the dried beetroots, obtained at a microwave power of $500 \mathrm{~W}$ (T4). The results showed that the content of betacyanin was the lowest $(3.38 \mathrm{mg} / \mathrm{g})$ in the beetroots, dried at a vacuum degree of $-0.05 \mathrm{MPa}$ (T1), while the lowest content $(2.52 \mathrm{mg} / \mathrm{g})$ of betaxanthin was observed in the beetroots with a sample thickness of $4 \mathrm{~mm}$ (T7).

Tahle 3

Bioactive compounds of beetroots dried by vacuum microwave drying conditions

\begin{tabular}{|c|c|c|c|c|}
\hline Treatment & $\begin{array}{c}\text { Betacyanin, } \\
\mathrm{mg} / \mathrm{g}\end{array}$ & $\begin{array}{c}\text { Betaxanthin, } \\
\mathrm{mg} / \mathrm{g}\end{array}$ & $\begin{array}{c}\text { Ascorbic acid, } \\
\mathrm{mg} / \mathrm{g}\end{array}$ & $\begin{array}{c}\text { Total flavonoid, } \\
\mathrm{mg} \mathrm{AE} / \mathrm{g}\end{array}$ \\
\hline T1 & $3.38 \pm 0.02^{\mathrm{f}}$ & $2.57 \pm 0.01^{\mathrm{d}}$ & $7.30 \pm 0.02^{\mathrm{e}}$ & $25.49 \pm 0.57^{\mathrm{b}}$ \\
\hline T2 & $3.65 \pm 0.02^{\mathrm{e}}$ & $2.79 \pm 0.01^{\mathrm{c}}$ & $8.35 \pm 0.09^{\mathrm{c}}$ & $22.37 \pm 0.57^{\mathrm{c}}$ \\
\hline T3 & $4.09 \pm 0.03^{\mathrm{c}}$ & $2.91 \pm 0.01^{\mathrm{b}}$ & $8.70 \pm 0.12^{\mathrm{b}}$ & $20.09 \pm 0.91^{\mathrm{d}}$ \\
\hline T4 & $4.65 \pm 0.03^{\mathrm{a}}$ & $3.34 \pm 0.06^{\mathrm{a}}$ & $10.96 \pm 0.04^{\mathrm{a}}$ & $28.34 \pm 0.44^{\mathrm{a}}$ \\
\hline T5 & $4.29 \pm 0.07^{\mathrm{b}}$ & $2.85 \pm 0.04^{\mathrm{bc}}$ & $7.94 \pm 0.12^{\mathrm{d}}$ & $26.04 \pm 0.49^{\mathrm{b}}$ \\
\hline T6 & $4.02 \pm 0.04^{\mathrm{cd}}$ & $2.82 \pm 0.01^{\mathrm{c}}$ & $7.89 \pm 0.06^{\mathrm{d}}$ & $25.92 \pm 0.49^{\mathrm{b}}$ \\
\hline T7 & $3.44 \pm 0.02^{\mathrm{f}}$ & $2.52 \pm 0.01^{\mathrm{d}}$ & $6.77 \pm 0.07^{\mathrm{f}}$ & $22.81 \pm 0.98^{\mathrm{c}}$ \\
\hline T8 & $3.97 \pm 0.00^{\mathrm{d}}$ & $2.83 \pm 0.00^{\mathrm{bc}}$ & $8.69 \pm 0.04^{\mathrm{b}}$ & $21.53 \pm 0.24^{\mathrm{c}}$ \\
\hline
\end{tabular}

Note: different superscript letters in the same column indicate significan differences $(p<0.05)$, and those with the same letters are not significantly different $(p>0.05)$

Ascorbic acid has a low stability during the heat treatment, so it is an important indicator of food processing quality. It has been reported, that the drying process can cause significant loss of ascorbic acid content [20]. The ascorbic acid content of dried beetroots was clearly influenced by vacuum degree and sample thickness $(p<0.05)$. The ascorbic acid content of dried beetroots increased with a rise in vacuum degree from -0.07 to $-0.09 \mathrm{MPa}$. There was no significant difference on the ascorbic acid content of beetroots, dried at a microwave power of $1000 \mathrm{~W}$ (T5) and $1500 \mathrm{~W}(\mathrm{~T} 6)(p>0.05)$. The highest ascorbic acid content $(10.96 \mathrm{mg} / \mathrm{g})$ was noted in dried beetroots, obtained at a microwave power of $500 \mathrm{~W}$ (T4), whereas the lowest ascorbic acid content $(6.77 \mathrm{mg} / \mathrm{g})$ was observed in beetroots with a sample thickness of $4 \mathrm{~mm}$ (T7).

A clear dependency between vacuum degree and total flavonoid loss was observed in beetroots, subjected to va- cuum microwave drying. With an increase in vacuum degree from -0.05 to $-0.09 \mathrm{MPa}$, there was a significant decrease in total flavonoid content $(p<0.05)$. It may be explained, that the degradation of betacyanin and betaxanthin lead to other flavonoid compounds. The beetroots, obtained at a vacuum degree of $-0.09 \mathrm{MPa}$ (T3), showed the lowest total flavonoid content, which was only $20.09 \mathrm{mg} \mathrm{RE} / \mathrm{g}$. The total flavonoid content of dried beetroots decreased with the increase of microwave power and sample thickness. The highest total flavonoid content (28.34 mg RE/g) of dried beetroots was appeared at a microwave power of $500 \mathrm{~W}$ (T4). An increase in microwave power led to a decrease in total flavonoid content. A similar result has been reported for microwave-vacuum drying of cranberries [21].

In this study, the beetroots, dried at a microwave power of $500 \mathrm{~W}$ (T4), showed the highest content of betacyanin, betaxanthin, ascorbic acid and total flavonoid.

3.4. Antioxidant activity of dried beetroots. Ferric reducing antioxidant power (FRAP) assay was selected to evaluate the antioxidant activity of dried beetroots, obtained at different vacuum microwave drying conditions, and the results are exhibited in Fig. 2.

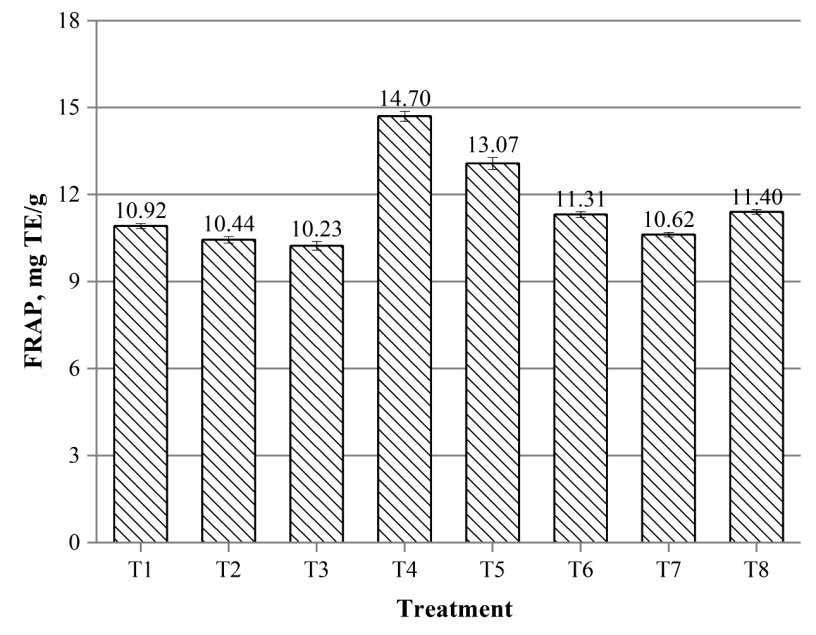

Fig. 2. FRAP values of dried beetroots affected by vacuum microwave drying conditions

The FRAP values of dried beetroots, obtained at different vacuum microwave drying conditions, were ranged from 10.23 to $14.70 \mathrm{mg} \mathrm{TE} / \mathrm{g}$. It can be seen, that FRAP decreased slightly with the increase of vacuum degree. The lowest FRAP of beetroots was obtained at a vacuum degree of $-0.09 \mathrm{MPa}$ (T3), which was only $10.23 \mathrm{mg} \mathrm{RE} / \mathrm{g}$. Meanwhile, FRAP values decreased significantly with the increase of microwave power $(p<0.05)$. It was clearly shown, that the dried beetroots, obtained at a microwave power of $500 \mathrm{~W}$ (T4), revealed the highest FRAP value (14.70 $\mathrm{mg} \mathrm{TE} / \mathrm{g}$ ). The highest FRAP value, as well as contents of betalain, ascorbic acid and total flavonoid were found in the beetroots, dried at a microwave power of $500 \mathrm{~W}$, indicating that ferric reducing ability was direct correlation to betalain, ascorbic acid and total flavonoid. The results are in agreement with the result of paper [21], who found that the increase in antioxidant activities of samples depends not only on the presence of betalains but also other polyphenols, which could have been increased during the treatments. Similar correlations were also reported in 
other studies about drying cranberries and bitter melon [22-24]. As shown in Fig. 2, no significant difference was found in FRAP values of dried beetroots with different sample thickness.

The iron reduction antioxidant capacity (FRAP) of dried beets decreased significantly with increasing microwave power and showed the highest value (14.70 $\mathrm{mg} \mathrm{TE} / \mathrm{g}$ ) at $500 \mathrm{~W}$ microwave power.

The most favorable conditions for vacuum microwave drying of beets were microwave power of $500 \mathrm{~W}$, vacuum degree of $-0.09 \mathrm{MPa}$, and sample thickness of $2 \mathrm{~mm}$. This leads to better physicochemical properties of biologically active compounds and a higher antioxidant activity of dried beets. Dried beetroots can be used as a functional food in food technology.

In this study, only one method (FRAP assay) was used to evaluate the antioxidant activity of dried beetroots. More methods should be employed to evaluate the total antioxidant capacity due to the different mechanisms of antioxidants. Moreover, it is necessary to avoid high temperature and long time treatment in the processing of beetroots. Dried beetroots prepared by vacuum microwave drying have a strong antioxidant capability, which can be used as antioxidants in foods.

\section{Conclusions}

This study analyzes the influence of microwave power, vacuum degree and sample thickness on the physicochemical properties and antioxidant activity of beetroots. The drying time, color, contents of betalain, ascorbic acid and total flavonoid, and FRAP values of beetroots were analyzed.

The results of this study revealed that microwave power, vacuum degree and sample thickness had significant effects on physicochemical properties and antioxidant activity of beetroots. The drying time decreased with increasing microwave power and vacuum degree, while increased significantly with the increase of sample thickness. The $L^{*}$ values of dried beetroots were higher than that of fresh beetroots. The values of $a^{*}$ were found to increase with the increase of vacuum degree. The values of $b^{*}$ increased with the increase of vacuum degree and microwave power, while reduced as the sample thickness added. The $\Delta E$ of dried beetroots reduced with increasing vacuum degree, and showed the lowest value at a vacuum degree of $-0.09 \mathrm{MPa}$. Contents of betacyanin and betaxanthin decreased with the growth of microwave power, while increased with the increase of vacuum degree. The ascorbic acid displayed an increasing tendency with the increase of vacuum degree, while decreased with the growth of microwave power. And the total flavonoid content of beetroots showed a declining tendency with the increase of vacuum degree, microwave power and sample thickness. FRAP values of beetroots decreased significantly with the increase of microwave power, and the highest FRAP value of dried beetroots was obtained at a microwave power of $500 \mathrm{~W}$.

In conclusion, appropriate microwave power, vacuum degree and sample thickness were conducive to maintaining better physicochemical properties and antioxidant activity of dried beetroots. Considering the bioactive compounds and antioxidant activity of dried beetroots, fresh beetroots with a thickness of $2 \mathrm{~mm}$, dried at a microwave power of $500 \mathrm{~W}$ and a vacuum degree of $-0.09 \mathrm{MPa}$, were proposed as the favorable drying conditions. Dried beetroots with high amount of bioactive compounds and strong antioxidant activity can be utilized as functional foods and value-added food products.

\section{Acknowledgements}

The authors would like to thank to Guangxi Key Laboratory of Health Care Food Science and Technology, Research Institute of Food Science and Engineering Technology, Hezhou University, China for providing laboratory facilities and technical support during this research work. We acknowledge the financial support from Guangxi Firstclass Discipline Food Science and Engineering Cultivation Project (GXYLXKP1816).

\section{References}

1. Chhikara, N., Kushwaha, K., Sharma, P., Gat, Y., Panghal, A (2019). Bioactive compounds of beetroot and utilization in food processing industry: A critical review. Food Chemistry, 272, 192-200. doi: https://doi.org/10.1016/j.foodchem.2018.08.022

2. Paciulli, M., Medina-Meza, I. G., Chiavaro, E., Barbosa-Cánovas, G. V. (2016). Impact of thermal and high pressure processing on quality parameters of beetroot (Beta vulgaris L.) LWT - Food Science and Technology, 68, 98-104. doi: https:// doi.org/10.1016/j.lwt.2015.12.029

3. Fu, Y., Shi, J., Xie, S.-Y., Zhang, T.-Y., Soladoye, O. P., Aluko, R. E. (2020). Red Beetroot Betalains: Perspectives on Extraction, Processing, and Potential Health Benefits. Journal of Agricultural and Food Chemistry, 68 (42), 11595-11611. doi: https://doi.org/10.1021/acs.jafc.0c04241

4. Slavov, A., Karagyozov, V., Denev, P., Kratchanova, M., Kratchanov, C. (2013). Antioxidant activity of red beet juices obtained after microwave and thermal pretreatments. Czech Journal of Food Sciences, 31 (2), 139-147. doi: https://doi.org/ $10.17221 / 61 / 2012$-cjfs

5. Hadipour, E., Taleghani, A., Tayarani-Najaran, N., TayaraniNajaran, Z. (2020). Biological effects of red beetroot and betalains: A review. Phytotherapy Research, 34 (8), 1847-1867. doi: https://doi.org/10.1002/ptr.6653

6. Nemzer, B., Pietrzkowski, Z., Spórna, A., Stalica, P., Thresher, W., Michałowski, T., Wybraniec, S. (2011). Betalainic and nutritional profiles of pigment-enriched red beet root (Beta vulgaris L.) dried extracts. Food Chemistry, 127 (1), 42-53. doi: https:// doi.org/10.1016/j.foodchem.2010.12.081

7. Scaman, C. H., Durance, T. D. (2005). Combined Microwave Vacuuum-drying. Emerging Technologies for Food Processing, 507-533. doi: https://doi.org/10.1016/B978-012676757-5/50021-9

8. Bórquez, R. M., Canales, E. R., Redon, J. P. (2010). Osmotic dehydration of raspberries with vacuum pretreatment followed by microwave-vacuum drying. Journal of Food Engineering, 99 (2), 121-127. doi: https://doi.org/10.1016/j.jfoodeng.2010.02.006

9. Shu, B., Wu, G., Wang, Z., Wang, J., Huang, F., Dong, L., Zhang, R., Wang, Y., Su, D. (2020). The effect of microwave vacuum drying process on citrus: drying kinetics, physicochemical composition and antioxidant activity of dried citrus (Citrus reticulata Blanco) peel. Journal of Food Measurement and Characterization, 14 (5), 2443-2452. doi: https://doi.org/ 10.1007/s11694-020-00492-3

10. Li, B., Fei, L., Liu, B., Nan, H. (2010). Microwave-vacuum drying characteristics and process optimization of Agaricus bisporus slices. Transactions of the Chinese Society of Agricultural Engineering, 26 (6), 380-384. doi: https://doi.org/10.3969/ j.issn.1002-6819.2010.06.066

11. Monteiro, R. L., Link, J. V., Tribuzi, G., Carciofi, B. A. M., Laurindo, J. B. (2018). Microwave vacuum drying and multiflash drying of pumpkin slices. Journal of Food Engineering; 232, 1-10. doi: https://doi.org/10.1016/j.jfoodeng.2018.03.015

12. Wang, J., Fang, X.-M., Mujumdar, A. S., Qian, J.-Y., Zhang, Q., Yang, X.-H., Liu, Y.-H., Gao, Z.-J., Xiao, H.-W. (2017). Effect of high-humidity hot air impingement blanching (HHAIB) on drying and quality of red pepper (Capsicum annuum L.) Food Chemistry, 220, 145-152. doi: https://doi.org/10.1016/ j.foodchem.2016.09.200 
13. Stintzing, F. C., Herbach, K. M., Mosshammer, M. R., Carle, R., Yi, W., Sellappan, S., Akoh, C. C., Bunch, R., Felker, P. (2004). Color, Betalain Pattern, and Antioxidant Properties of Cactus Pear (Opuntia spp.) Clones. Journal of Agricultural and Food Chemistry, 53 (2), 442-451. doi: https://doi.org/10.1021/jf048751y

14. De Souza, V. R., Pereira, P. A. P., da Silva, T. L. T., de Oliveira Lima, L. C., Pio, R., Queiroz, F. (2014). Determination of the bioactive compounds, antioxidant activity and chemical composition of Brazilian blackberry, red raspberry, strawberry, blueberry and sweet cherry fruits. Food Chemistry, 156, 362-368. doi: https://doi.org/10.1016/j.foodchem.2014.01.125

15. Benzie, I. F. F., Strain, J. J. (1996). The Ferric Reducing Ability of Plasma (FRAP) as a Measure of «Antioxidant Power»: The FRAP Assay. Analytical Biochemistry, 239 (1), 70-76. doi: https://doi.org/10.1006/abio.1996.0292

16. Tian, Y., Wu, S., Zhao, Y., Zhang, Q., Huang, J., Zheng, B. (2015). Drying Characteristics and Processing Parameters for Microwave-Vacuum Drying of Kiwifruit (Actinidia deliciosa) Slices. Journal of Food Processing and Preservation, 39 (6), 2620-2629. doi: https://doi.org/10.1111/jfpp.12512

17. Ng, M. L., Sulaiman, R. (2018). Development of beetroot (Beta vulgaris) powder using foam mat drying. LWT-Food Science and Technology, 88, 80-86. doi: https://doi.org/10.1016/ j.lwt.2017.08.032

18. Sremet (Ceclu), L., Nistor, O.-V., Andronoiu, D. G., Mocanu, G. D., Barbu, V. V., Maidan, A., Rudi, L., Botez, E. (2020). Development of several hybrid drying methods used to obtain red beetroot powder. Food Chemistry, 310, 125637. doi: https:// doi.org/10.1016/j.foodchem.2019.125637

19. Székely, D., Vidák, K., Furulyás, D., Ribárszki, Á., Stéger-Máté, M. (2019). Effect of drying methods on physicochemical parameters of different red beetroots (Beta vulgaris L.) species. Periodica Polytechnica Chemical Engineering, 63 (3), 485-490. doi: https:// doi.org/10.3311/PPch.13104

20. Handwerk, R. L., Coleman, R. L. (1988). Approaches to the citrus browning problem. A review. Journal of Agricultural and Food Chemistry, 36 (1), 231-236. doi: https://doi.org/10.1021/ jf00079a057
21. Ravichandran, K., Saw, N. M. M. T., Mohdaly, A. A. A., Gabr, A. A. A., Kastell A., Riedel, H., Cai, Z. Z., Knorr, D., Smetanska, I. (2013). Impact of processing of red beet on betalain content and antioxidant activity. Food Research International, 50 (2), 670-675. doi: https://doi.org/10.1016/j.foodres.2011.07.002

22. Vega-Gálvez, A., Di Scala, K., Rodríguez, K., Lemus-Mondaca, R. Miranda, M., López, J., Perez-Won, M. (2009). Effect of airdrying temperature on physico-chemical properties, antioxidant capacity, colour and total phenolic content of red pepper ( $\mathrm{Cap}$ sicum annuum, L. var. Hungarian). Food Chemistry, 117 (4), 647-653. doi: https://doi.org/10.1016/j.foodchem.2009.04.066

23. Zielinska, M., Zielinska, D. (2019). Effects of freezing, convective and microwave-vacuum drying on the content of bioactive compounds and color of cranberries. LWT-Food Science and Technology, 104, 202-209. doi: https://doi.org/10.1016/j.lwt.2019.01.041

24. Nguyen, T.-V.-L., Nguyen, Q.-N., Nguyen, P.-B.-D., Tran, B.-L., Huynh, P.-T. (2020). Effects of drying conditions in low-temperature microwave-assisted drying on bioactive compounds and antioxidant activity of dehydrated bitter melon (Momordica charantia L.), Food Science and Nutrition, 8 (7), 3826-3834. doi: https://doi.org/10.1002/fsn3.1676

Yan Liu, Postgraduate Student, Department of Engineering Technologies for Food Production, Sumy National Agrarian University, Sumy, Ukraine; School of Food and Biological Engineering, Hezhou University, Hezhou, China, ORCID: https://orcid.org/0000-0002-6322-7013

$\triangle$ Sergei Sabadash, PhD, Associate Professor, Department of Engineering Technologies for Food Production, Sumy National Agrarian University, Sumy, Ukraine, ORCID: https://orcid.org/0000-00020371-8208, e-mail: s.v.sabadash@ukr.net

Zhenhua Duan, PhD, Professor, School of Food and Biological Engineering, Hezhou University, Hezhou, China, ORCID: https:// orcid.org/0000-0002-9283-3629

$\triangle$ Corresponding author 